\title{
TOWARDS A HUMEAN EPISTEMIC IDEAL: CONTESTED ALTERNATIVES AND THE IDEOLOGY OF MODERN SCIENCE ${ }^{1}$
}

\begin{abstract}
I suggest that it is fruitful to read Hume's Enquiry concerning Human Understanding as a concise exposition of an epistemic ideal whose complex philosophical background is laid down in A Treatise of Human Nature. Accordingly, the Treatise offers a theory of cognitive and affective capacities, which serves in the Enquiry as the foundation for a critique of chimerical epistemic ideals, and the development of an alternative ideal. Taking the "mental geography" of the Treatise as his starting point, this is the project Hume pursues in the Enquiry. The epistemic ideal Hume spells out in the Enquiry is an alternative to competing ideals: the Aristotelian, the Cartesian, and the Newtonian, and can be read as an exposition of the epistemic ideal of modern science. Although the spell of the Aristotelian and the Cartesian ideals had been in decline for several decades by the 1740s, they had not fully lost their grip on the philosophical imagination. Yet, it was the Newtonian epistemic ideal that became dominant in Scotland and Britain by then, guiding inquiry in moral and natural philosophy, as well as in medical theory. Hume offers a critique of these ideals. He shows that Aristotelian and Cartesian epistemic aspirations rest on mistaken views on human cognitive capacities. And albeit the Newtonian ideal is not prone to this mistake by Hume's standards, its epistemic expectations extend far beyond the limits of those capacities. Hume's epistemic ideal can be read as a correction, limitation and refinement of the Newtonian ideal: it sets epistemic aims and propagates methods for the production of fallible, limited and potentially useful knowledge that falls short of the great epistemic expectations of Newton and many Newtonians - but it conforms to what we expect from modern science.
\end{abstract}

Keywords: Hume, epistemic ideals, scientia, demonstrativity, Aristotle, Descartes, Newton

\section{Introduction}

Robert Pasnau $(2013,2017)$ has argued inspiringly that historically speaking, epistemology had been centred on the exposition of epistemic ideals - and the focus on the conceptual analysis of 'knowledge' would gain

1 This paper contributes to the research programme of MTA Morals and Science Lendület Research Group. I am grateful for comments and suggestions to the members of the group, particularly Gábor Bíró, Péter Hartl, Gergely Kertész, Gábor Zemplén and Deodáth Zuh. 
prominence only in the twentieth century, so the history of philosophy teaches that "a theory of knowledge ought not to be a theory of "knowledge" (Pasnau 2017, 11). Epistemologies aiming at the development or refinement of epistemic ideals have not been preoccupied with the necessary and sufficient conditions to meet when we apply 'knowledge' to some epistemic state of persons: if 'knowledge' is taken to express an epistemic ideal that inquiry should approach, then the ideal itself may remain unattainable and yet orient successfully towards desirable aims and methods. Aristotle's own writings, for example, "contain no examples that satisfy all the necessary requirements" of episteme (ibid. 5) - an ideal whose central tenets had been dominating epistemological thinking up until about the eighteenth century. So, epistemic ideals are proposed with an eye to what our inquiries should aspire to even if it is impossible to achieve. Just like conceptual analysis, constructing epistemic ideals is also a normative enterprise, but in a different way: they do not inspire to demarcate cases of knowledge from non-knowledge, but to provide motivation and guidelines for inquiry. An epistemic ideal shows what inquiry should achieve and how it should achieve it - never mind that "we commonly fall off from that ideal" (ibid. 3).

Epistemic ideals can be developed only as part of complex philosophical systems, because they presuppose a metaphysical apparatus and a theory of cognitive capacities. In order to formulate an epistemic ideal, one needs a theory of what can be known at all - and one has to answer questions about how, and to what extent, our cognitive capacities are suited to provide access to those possible objects of knowledge. Plato's epistemology would be incomprehensible without his theory of Forms, Aristotle's episteme presupposes his essentialism, and Cartesian science rests on the foundations of a metaphysics of modes, etc. So, an "epistemic ideal depends critically on how one conceives of the world" (ibid. 58). This account of what the world consists of has to be accompanied by a theory of perception and reasoning - the two ways human beings can gain epistemic access to the world. How brave our epistemic expectations can be, how their prospects and limits could be articulated depend on these cognitive and metaphysical considerations.

Here I am going to suggest that it is fruitful to read Hume's Enquiry concerning Human Understanding (1748, hereafter EHU) as a concise exposition of an epistemic ideal whose complex philosophical background is laid down in A Treatise of Human Nature (1739/40, hereafter T). As I do not have the space here to dwell on the background the Treatise provides, I only indicate that I consider this suggestion consonant with Hsueh Qu's recent work. Qu (2020), rightly I think, points out a crucial difference between the projects of the Treatise and the Enquiry: epistemological issues in the Treatise tend to arise "as offshoots of psychological discussions" (ibid. 5), while the Enquiry is "much more epistemological in nature" (ibid. 6). The fundamental ambition of the Treatise is "to conduct the study of human nature as a science" 
(ibid. 41), while in the Enquiry "this philosophical undertaking is not taken as an end in itself, but it is rather instrumental towards the epistemic goal of destroying false philosophy" (ibid. 43). This latter project can be fruitfully explained in terms of epistemic ideals. The Treatise offers a theory of our cognitive and affective capacities, which serves in the Enquiry as a foundation for a critique of chimerical epistemic ideals, and the development of an alternative ideal. Taking a "mental geography" as his starting point (EHU 1.13), this is the project Hume pursues in the Enquiry.

The epistemic ideal Hume spells out in the Enquiry is an alternative to competing ideals: the Aristotelian, the Cartesian, and the Newtonian, and can be read as an exposition of an epistemic ideal of modern science. The spell of the Aristotelian and the Cartesian ideals had been in waning for several decades by the 1740s, they had not fully lost their grip on philosophical imagination. Yet, it was the Newtonian epistemic ideal that became the dominant force by then, guiding inquiry in moral and natural philosophy, as well as in medical theory. ${ }^{2}$ Hume offers a critique of these ideals. He shows that Aristotelian and Cartesian epistemic aspirations rest on mistaken views on human cognitive capacities. And although the Newtonian ideal comes much closer to Hume's standards, it also tends to extend its epistemic expectations far beyond the limits of those capacities. Hume's epistemic ideal is thus a correction, limitation and refinement of the Newtonian ideal: it sets epistemic aims and propagates methods for the production of fallible, limited and potentially useful knowledge that falls short of the great epistemic expectations of Newton and many Newtonians - but it conforms to what we expect from modern science.

In the context of competing epistemic ideals, the project of the Enquiry can be framed with an eye on contemporaneous genres of knowledge production and the epistemic concepts integrating them. This philosophical project begins with clarifying crucial epistemic concepts such as experience, reasoning, inference, induction, probability, causation, explanation and testimony. In this respect, the aim of the Enquiry is to chase out "obscurity in the profound and abstract philosophy" (EHU 1.11) by the "spirit of accuracy" (EHU 1.9). The nature of "accurate and just reasoning" to be deployed in these matters can be revealed only "from an exact analysis of [our cognitive] powers and capacity" (EHU 1.12). The Enquiry, however, does not provide such an analysis but rather invokes its results: the task of analysis had already been taken up in the Treatise and produced an "anatomy" of the mind ( $\mathrm{T}$ $\mathrm{T}$ 1.4.6.23, 2.1.5.6 and 8, 2.2.11.6, 2.1.12.2, 3.3.6.6, A.2, see also EHU 1.8, 7.9). ${ }^{3}$ Against this background the Enquiry is left with the task of subverting "abstruse philosophy and metaphysical jargon" and "cultivat[ing] true

2 I discuss several aspects of this situation in Demeter 2016.

3 I sketch the character of this anatomy in Demeter 2016 ch.8 and more recently in Demeter 2021. 
metaphysics" (EHU 1.12) by revealing the content that epistemic concepts can legitimately have, given their genealogy in human nature.

These epistemic concepts play a foundational and integrative role: epistemic practices, from observation to theory construction, are organized around them. Exposing their "distinct meaning", "nature" and "reality" (as suggested in EHU 2.9) reveals the kinds and the strength of knowledge claims that they can support in various genres of knowledge production, and thereby it reveals what kind of epistemic benefit we can hope from the practices organized around them. Hume's analyses define an epistemic ideal: they show what our expectations should be concerning our evidential, inferential, explanatory and predictive practices as integrated by these concepts. Relying on an empiricist genealogy of these concepts, Hume outlines what we can expect from institutionalized genres of knowledge production: natural and moral philosophy, mathematics, and theology. Following a critique of alternative epistemic ideals and a critique of epistemic concepts, a critique of the genres of knowledge production constitutes the third angle from which Hume's epistemic ideal can be characterized.

This paper focuses only on the first step of this programme for reconstructing Hume's epistemic ideal, namely the alternative stances against which Hume's ideal is unfolding. Locating Hume's epistemic ideal in the proper historical context in this way is important, because the elaboration of epistemic ideals is a cooperative process that brings about advances in metaphysics and epistemology and results in a refined and complex epistemic ideal. But Hume's Enquiry is rather concise, and we should not expect detailed critiques of competing ideals in it. Hume's challenge is advanced only against some of their core elements.

\section{The Aristotelian ideal}

Historically, Aristotle's episteme, subsequently known as scientia, was unquestionably the most influential and persistent epistemic ideal, several tenets of which survived even in the works of those criticizing it. ${ }^{4}$ This ideal has its roots in Aristotelian logic: according to Aristotle's Posterior Analytics, knowledge worthy of its name must consist of propositions that are universally and necessarily true. This necessity must be demonstrated through syllogistic inferences that proceed from premises containing the cause of the conclusion. This procedure leads to certain knowledge and understanding of the necessary cause of the phenomena and an explanation of why it is the way it is and cannot be otherwise. Being necessary and universal, this knowledge is focused on the essential structure of things, and through their essences it accounts not only for how things actually behave, but also for how they would behave in a variety of circumstances. Accordingly, knowledge or scientia consists in a

4 See Pasnau (2017), and for a more concise overview see Demeter, Láng, Schmal (2016). 
systematic, demonstrative presentation of why things behave the way they do - and not in the discovery of the causes from which demonstrations followed.

Even if this ideal had never been fully implemented in epistemic practice (not even by Aristotle himself, see Pasnau 2013, 993), it served as the guide of systematic inquiry for several centuries. Particularly, Aristotelianism had been a definitive force in Scottish philosophy well into the eighteenth century (Sgarbi 2013, 44-51), and the Aristotelian ideal was not yet a thing of the past in Hume's time. While studying in Edinburgh, Hume might have been exposed to the Aristotelian ideal in Colin Drummond's class centred on syllogism and Aristotelian metaphysics, which "gave Hume an edifice to destroy, not a path to follow" (Harris 2015, 39). And the influence of Aristotelian logic of inquiry extended beyond the time of Hume's education in the 1720s: Thomas Reid in 1774 still considered it a worthwhile undertaking to point out the many features of Aristotle's logic that prevent it from being a useful "engine of science" (Reid 1872, 1:701-702).

Repeated experience has a crucial role to play in the Aristotelian ideal: it is supposed to provide access to the essence of phenomena from which demonstrations can follow. At this point Aristotelian method and metaphysics are combined, so the ideal of episteme entails essentialism. Although Hume is not an enemy of experimental inquiry into the hidden compositions and structures, ${ }^{5}$ he also holds that the "ultimate springs and principles are totally shut up from human curiosity and enquiry" (EHU 4.12), and that no amount of experience can help us in this regard. With the help of experience we can "resolve the many particular effects into a few general causes" (EHU 4.12), and that by such causal reasoning we can attain some "assurance concerning objects, which are removed from the present testimony of our memory and senses" (EHU 7.29). Consequently, our inductive practices lend some credibility to our inferences concerning "secret powers" (EHU 4.21) that might be resolved further by the help of experience, but even the "most perfect philosophy of the natural kind only staves off our ignorance a little longer" (EHU 4.12). ${ }^{6}$ So, no knowledge of Aristotelian essences is to be hoped for.

As for Aristotelian methodology, it is less than ideally clear how the step from particular experiences to universal essences is to be taken, but the Organon provides at least two possibilities for understanding Aristotelian induction. One way is to claim that the inductive step is intuitive, so that "from several particulars the universal is clear" (88a4 see also 100b4-5). Induction so understood is "a natural psychological process by which intuition of self-evident truths develops in us over time" (Salmieri 2014, 3 ). The other possibility (suggested e.g. in 156b10-16) is to take induction

5 Different versions of what Humean inquiry into hidden structures means are presented by Landy (2018) and Demeter (2020).

6 Elsewhere I argued that these passages in Hume can be fruitful to read as expressing commitment to a version of constructive empiricism (see Demeter 2020). 
as an argument from the particulars to the universal (see also Smith 2017, 3.1). Either way, as a result of induction we get a view of the intelligible form beyond the perceptual form of phenomena - i.e. a view beyond what is given in experience, and it reveals to us what it is that is given in experience (see also Buckle 2001, 91). This view is an epistemic state that Aristotle calls nous, the apprehension of essences as the causes from which phenomena can be demonstrated as necessary effects arising from necessary causes. This demonstrative knowledge constitutes episteme or scientia.

Hume's Enquiry can be read as arguing that the epistemic burden repeated experience is supposed to carry in the Aristotelian ideal is much bigger than on philosophical scrutiny it can bear. In Section 4 Hume undermines the suggestion that "uniform experience" can lead to knowledge through reasoning and reflective inference. In the form of a poetic question whose answer he cannot even imagine, he points out that there is no "process of reasoning, which, from one instance, draws a conclusion, so different from that which it infers from a hundred instances, that are nowise different from that single one" (EHU 4.20, se also 4.21). Repetition and uniformity of experience can only lead to the conclusion that similar causes have "always been attended with" similar effects, but they cannot establish universal conclusions that the same causes will, let alone must, be attended with the same effects - as Aristotelian scientia would require. There is no intuitive step leading from "always" to "will" or "must", nor to the missing intermediate steps between them for drawing the inference needed (EHU 4.16).

While in the Aristotelian ideal repeated experience is supposed to lead to an epistemic state (nous) by intuition or reasoning, in Hume's alternative picture the immediate yield of repeated experience is only an "instinct or mechanical tendency" distinct from our reflective inferential capacities (EHU 5.22). This tendency, namely custom, brings along a doxastic state that is "felt by the mind" (EHU 5.12) - i.e. an affective rather than an intellectual state of mind. The mechanical tendency inculcated by repeated experience can only give rise to an impression of reflection, but no intuition: it can only yield an expectation that directs the course of our ideas in our inferences concerning factual matters. Consequently, the idea of cause turns out to be a sense-based concept in Hume's hands (Garrett 2015, 129-136).

The doxastic state arising due to repeated experience is much more malleable than scientia. It is not related to essences, cannot aspire to universality and certainty, but it is open to revision: the course of our experience can change, and even more likely, new experience can change the doxastic state itself. Hume's account of what repeated experience can deliver is thus more congruent with the Newtonian ideal of open-ended inquiry where experimental knowledge is the basis of further inquiry - and not the foundation of ultimate knowledge (see e.g. Smith 2002, 160-161). 


\section{The Cartesian ideal}

The Cartesian epistemic ideal emerged as an influential and effective alternative to the Aristotelian. The Cartesian ideal diverged in several respects from the Aristotelian while preserving some of its characteristics, most notably its aspiration for demonstrativity and certainty. Descartes was still devoted to the ideal of scientia insofar as the aspiration to certainty is concerned. This certainty, however, was not supposed to be reached through demonstration by syllogistic inference that Descartes severely criticized as a useless logical instrument for delivering knowledge. Instead, he advocated a method of analysis and synthesis: breaking down complex questions into simple ones to which intuitively clear and distinct answers can be given and then to proceed from these intuitive answers to answering complex questions. The demonstrativity of this process is preserved by grasp of intuitive truths: each step in the process follows intuitively from the previous one. The reliability of this process is not due to the rules of syllogistic logic, but the benevolence of God, because it entails that God does not intend to deceive, and so it guarantees the reliable functioning of our faculties in the process of cogitatio (CSM 2:109-111).

The core of the Cartesian ideal is thus, similarly to the Aristotelian, a combination of metaphysics and method. Its metaphysics presented the world as consisting of two kinds of substance: matter whose essential attribute is extension, and whose properties are all modes of extension - and mind whose essential attribute is thinking, and whose properties are all modes of thinking. Its method is focused on the analysis of complex problems into simpler ones in a deductive manner until reaching those problems that are prone to "clear and distinct" answers by means of intuition - just like the most basic questions in mathematics. This method is supposed to guarantee the demonstrativity and certainty of the insights our inquiries can deliver.

The Cartesian method was focused on clear and distinct ideas, to be reached either by intuition or by the method of analysis, from which explanations could be constructed by synthesis. This method is formulated as Rule 5 for the direction of the mind: ${ }^{7}$

The whole method consists entirely in the ordering and arranging of the objects on which we must concentrate our mind's eye if we are to discover some truth. We shall be following this method exactly if we first reduce complicated and obscure propositions step by step to

7 Garber $(2001,35)$ denies this is a reference to analysis/synthesis, and he breaks with the tradition that treats these passages so. He would rather reserve analysis/synthesis as modes of theory construction. Smith $(2010,67,84-86)$ is convenient to talk about the method advocated in the Rules in terms of analysis/synthesis. Jardine $(1974,249)$ gives a list of several terms that were used as synonymous in the period, and the wording of Rule 5 conforms to it. 
simpler ones, and then, starting with the intuition of the simplest ones of all, try to ascend through the same steps to a knowledge of all the rest. (CSM 1:20)

These two phases of method can come apart depending on the ideas involved in our inquiries. In geometry, for example, we can begin demonstrations in the phase of synthesis because they "deal only with the simplest and most general things" (CSM 2:14), so the "primary notions" here are "readily accepted by anyone" (CSM 2:111). Therefore, we can begin instantly with clear and distinct postulates, axioms, and definitions. In metaphysics, however, the "primary notions" are not at all clear in the first instance, so they must be excavated: they must be made clear and distinct by the means of analysis. And there are, of course, complex geometrical problems where synthesis can only be "a follow-up to analysis" (CSM 2:111; see e.g. the Pappus problem, Bos 2001, ch.23), and Descartes seems to suspect that even the clearest and most ancient examples of geometrical syntheses rested on analysis (CSM 2:111). So, both analysis and synthesis are geometrical methods of demonstration (CSM 2:110).

The Cartesian understanding of matter in terms of extension invites inquiry into nature to be conducted with geometrical methods. Consequently, it is natural to expect the same kind of knowledge from natural philosophy as from geometry. As Rule 5 above prescribes, inquiry should consist in the analysis of complex propositions into simple ones until reaching those that are susceptible of intuitive answers in terms of the primary objects of intuition: "simple natures". Their class includes e.g. 'cause', 'the one', 'the equal', 'thought', 'will', 'shape, 'extension', 'motion' etc. and our acquaintance with them is "derived from the light of reason" (Garber 1992, 33). Garber (2001, 37) reconstructs a series of such reduction from the complex question of "What is the shape of a line (lens) that focuses parallel rays of light to the same point?" to "What is a natural power?" Once this question is answered by means of intuition we can "ascend through the same steps" answering eventually the initial question with as much clarity and certainty as the bottom question has been answered. ${ }^{8}$

This process of analysis results in a "hierarchical conceptual structure" (Smith 2010, 89) in whose discovery (in the phase of analysis) and deployment (in the phase of synthesis) experience has only an auxiliary role to play. While "we can use the connections we find in nature as a guide to the connections we seek in reason" (Garber 102), the epistemic burden is carried by deductions and clear and distinct intuition. So, experience can help structuring the process of reduction until we reach the unanalyzable question at the bottom that intuitively clear answer is to be given. Then in the phase of synthesis we can provide causal explanations by deriving observed phenomena from

8 A more complex example is shown in the deduction of the cause of the rainbow, see Garber 2001, 100. 
intuitively clear principles. As Garber $(2001,119)$ points out, experience here plays a role similar to that of diagrams in geometry: whatever actual visual experience, measurement and construction tell us about objects of geometry, geometrical knowledge is attainable only through the proof of a theorem. "Observation and experiment may play an important role in establishing an experimental fact, but it is reason that must confer the ultimate status of facthood on an observation" (Garber 2001, 313-314).

The Cartesian ideal did not enjoy a prolonged popularity in Scotland (see Shepherd 1982, Barfoot, 1990, Wilson 2009, 1-32). From the 1680s onwards, Gilbert McMurdo and Alexander Cockburn adopted Cartesian ideas, and they spread the mechanical worldview among their students, as was the case with most of their fellow regents in Edinburgh at that time. Until about 1690 Cartesianism prevailed in natural philosophy with a focus on the idea of rotating transparent matter causing the planets to orbit in the same direction and explaining why objects are falling toward the earth's surface. After the publication of Newton's Principia, forces quickly populated the mechanical universe and gravity replaced vortices in the explanation of planetary motions. The transformation of Cartesianism into Newtonianism took place in Edinburgh fairly rapidly, and by about 1710 the triumph of Newtonianism was eminent at the other Scottish universities as well.

Descartes was an important inspiration behind the construction of Hume's Treatise. This should not come as a surprise as its composition took place mostly at the Royal College at La Flèche which "was a good place to read Descartes and to learn about Cartesianism" (Perinetti 2018, 65). In a letter dated 26/8/1737, Hume suggested to Michel Ramsay that reading Descartes's Meditations might prove to be useful for understanding the metaphysical disquisitions in his then only forthcoming work (Norton and Norton 2007, 443). Descartes's Second Replies (esp. CSM 2:110-111 discussed above) reveal how important the methodological lessons of the Meditations are. And arguably, the sharpest contrast between Descartes's and Hume's projects can be drawn in terms of method (see e.g. Wright 2009, 43), and this contrast is reflected in Hume's normative epistemology.

At the beginning of Section IV Hume's taking out the fork of the drawer sets the scene: by putting "matters of fact" and "relations of ideas" on two different epistemological plains (EHU 4.1), Hume exposes the gap on which the Cartesian methodology was built. ${ }^{9}$ From Hume's perspective Descartes's deductive, and by Hume's standards a priori, ${ }^{10}$ method is untenable for inquiries into matters of fact, because those inquiries, as Hume keeps

9 Buckle (2001, 158-159), drawing on different pool of references disagrees with the claim that Descartes is the target here, but he also says: "Hume's argument concerns a view that founds knowledge on veridical perceptions from which reason establishes a system of knowledge." In the present reconstruction, this is the idea underlying Descartes's method.

10 A priori in Descartes has different connotations from Hume's and from the modern (post-Humean and post-Kantian) sense of the term, see Smith 2010, 67-69. 
emphasizing, can only be directed by experience, observation, and analogy (EHU 4.12, 9.1, 5, 10.10, 11.27, 30,) - not by reason (EHU 4.7, 14). As all reasoning concerning matters of fact rely "on the relation of Cause and Effect" (EHU 4.4), and as this relation can be known exclusively from experience, it is hopeless to aspire to causal explanations that rely on deductions and intuitions. Cartesian "simple natures" cannot guide our inferences here, Hume because, according to Hume: "Solidity, extension, motion; these qualities are all compleat in themselves, and never point out any other event which may result from them" (EHU 7.8).

Consequently, the primary objects of inquiry must be those of experience and not of reason. Instead of resolving complex problems with methods akin to those of geometrical analysis, Hume proposes to "resolve the many particular effects into a few general causes, by means of reasonings from analogy, experience, and observation" (EHU 4.12). So, instead of $a$ priori, geometrical approach to propositions, Hume advocates a comparative empirical approach to the phenomena themselves. These inquiries are, by the nature of experience, limited and fallible: they cannot produce ultimate and certain knowledge, but there is no other way at our disposal than the way of experience. And applying geometry in this field cannot be a remedy. For Descartes, geometry (analysis) plays the leading role in discovery, experience is only auxiliary; for Hume all the discovery of a matter of fact such as a law of nature "is owing merely to experience" and geometry can only "assist" us (EHU 4.13). A priori reasoning of any sort cannot help us in discovery, because then we could only consider an object "as it appears to the mind, independent of all observation" (EHU 4.13), and this consideration cannot lead us to anything distinct from the object - particularly it cannot suggest its effect or cause (EHU 4.11).

If despite all this, one still thinks it meaningful to undertake a Cartesian project of analysis and synthesis, then one fell prey to the appearance that custom induces: with respect to the familiar course of nature we imagine we can infer the effects "by the mere operation of our reason, without experience" (EHU 4.8). The Cartesian epistemic ideal is inspired by this deception rooted deeply in human nature - and given human nature, reason must give way to experience as the engine of inquiry.

\section{The Newtonian ideal}

When Hume attended Edinburgh University in the early 1720s, the culture of inquiry was dominated by Newtonianism, and due to the work of David Gregory, John Keill and Colin Maclaurin, the influence of Scottish Newtonians extended well beyond the Scottish borders (see Wilson 2009, 34-59). Generally speaking, Hume was disappointed with the education he 
received at the university and he had a very low opinion on the knowledge to be acquired there. One exception, at least to some extent, seems to be the natural philosophy class, which was taught to him by Robert Steuart (Stewart $2005,25)$. In Steuart's class Hume presumably was required to study Keill's introductions to natural philosophy and astronomy, Gregory's introduction to optics and astronomy along with certain passages from Newton's Opticks and Principia (ibid. 21-22). Also, he probably made good use of the Physiological Library Steuart had established, which might have provided him with all the relevant literature he needed for an introduction to the problems of contemporary natural philosophy.

Newton's epistemic ideal went through significant changes, some of them due to the controversies arising in the aftermath of his new theory of light and colours, published in 1672 (see Zemplén and Demeter 2010). Initially, Newton was insisting on the idea that colour phenomena can be treated with mathematical certainty, and considered his famous experimentum crucis as outright demonstrative (Turnbull 1960, 80). On this basis he maintained that "the Science of Colours will be granted Mathematicall \& as certain as any part of Opticks" (Turnbull 1959, 187). His confidence would be shaken subsequently. First, he retreated to the claim that optics operates with physical principles and mathematical demonstrations: physical principles constrain certainty, but if they are true, the conclusion of mathematical reasoning founded on them is demonstratively true (Turnbull 1959 p. 187-188). Then finally he proclaimed in Query 31 of the 1717 edition of the Opticks that "arguing from experiments and observations be no demonstration of general conclusions, yet it is the best way of arguing which the nature of things admits of" (Newton 2004, 138).

This can be read as an admission of failure to extend mathematical analysis at least to certain parts of nature - an admission that amounts to giving up the ambitions of the Principia. Newton's method in the Principia is focused on an analysis of motions and the forces producing them, and he makes it not less than "the basic problem of philosophy ... to discover the forces of nature from the phenomena of motions and then to demonstrate the other phenomena from these forces" (Newton 2004, 41). In the case of colours Newton had to give up his initial hopes for a demonstrative mathematical exposition that he had achieved for fits and refrangibility (Cohen 1980, 138140). This might motivate Newton's permission for a potentially qualitative (as opposed to mathematical) analysis of "compounds to ingredients" as a route to explanatory principles in Query 31 of Opticks, and also his entertaining the possibility of accounting for optical phenomena as chemical phenomena (Shapiro 1993, 142n16). Eventually he had to allow for an experimental decomposition of white light into its component colours, but he had to stop short of giving it a full mathematical treatment in terms of motions and forces acting on light corpuscles (Guicciardini 2009, 316-317). 
Hume's epistemic ideal is not consonant with the mathematically focused "strong program of mechanical natural philosophy" (Reill 2003, 27n14), a programme that, following Galileo's and Descartes's footsteps, was completed by Newton's Principia and had also been represented in his early optical inquiries. For Hume, mathematics is a useful tool in the practical applications of natural philosophy, but not in discovery: it is not possible to have a demonstrative, mathematical science about matters of fact, because the discovery of laws and our ability to draw causal inferences are owing exclusively to experience. So, "it is a law of motion, discovered by experience, that the moment or force of any body in motion is in the compound ratio or proportion of its solid contents and its velocity" and geometry can only assist us only when we are to apply this law e.g. to establish the proportions of mass and velocity when we are to move a great weight "by contrivance or machinery" (EHU 4.13, for a similar point see also $\mathrm{T}$ 2.3.3.2).

Given Hume's fork, this should not be surprising (see Slavov 2017). Natural philosophy, being concerned with matters of fact, cannot be based on mathematical principles, because they lack empirical content, so they cannot serve as the model of reality. Natural philosophy cannot apply mathematical methods of reasoning either, because "the only objects of the abstract science or of demonstration are quantity and number, and that all attempts to extend this more perfect species of knowledge beyond these bounds are mere sophistry and illusion" (EHU 12.27). So, mathematics cannot be a guide or model in our reasoning about matters of fact, and it cannot be seen as a guide for revealing the structure of the world. Mathematics just cannot be the meaningful language in which the book of nature is written - and this disqualifies the programme of the Principia as an epistemic ideal desirable by Hume's standards.

However, arguing from experiments and observations is, by Hume's standards, indeed the best (actually, the only) way if we aspire to epistemic benefits with respect to matters of fact - just as Newton proclaims in Query 31. Arguing this way, as is already clear (in EHU 4.12 discussed above), is arguing by analogies founded on similarities: "From causes, which appear similar, we expect similar effects. This is the sum of all our experimental conclusions" (EHU 4.20). Being founded on similarity, analogy also comes in degrees (see EHU 4.7-8, 4.20, 10.10 and esp. 9.1), and we can rely on it in our inferences only so far as similarity extends. Yet, we have a tendency to overstretch similarities and thus to violate the "rules of analogy" (EHU 11.27) by drawing inferences without being entitled to them.

This also means that the knowledge we can derive from such reasoning is fallible. There are uncertainties and irregularities in the course of events, so similarities can only lead us only to probable conclusions (EHU 6.4). Where no such irregularities occur, uniform experience can amount to "proof" (EHU 6.5) that leaves "no room for doubt or opposition" (EHU 6, n10). But even in these cases our certainty is not fallible, because it is not demonstratively 
true that the course of nature will not change (EHU 4.18). Even experience combined with mathematics is still experience and arguments put forward this way (as in "mixed mathematics") can only aspire to the status of "proof" and never to that of "demonstrations" (EHU 6, n10). 11 Striving for demonstrative knowledge of nature is thus doomed by the very nature of experience and experimental reasoning. This seems to be the conclusion Newton himself draw as a result of the controversy ensuing after his attempt at a demonstrative experimental science of colours (Zemplén and Demeter 2010, 651). This insight is also present in the way Hume draws and treats the distinction between proofs and demonstrations in the Enquiry (EHU 6, n10) - a distinction that is consonant with Newton's typical usage.

Beyond the questions of demonstrativity and the applicability of mathematical methods to inquiry into matters of fact I take Hume's epistemic ideal to be largely consonant with Newton's in several respects (see Demeter 2019a). ${ }^{12}$ The emphasis on what is actually observed is an expression of epistemic humility that was perceived as a Newtonian epistemic virtue and was expressed in various contexts, most famously perhaps with respect to the cause of gravity (Newton 2004, 100). Due to the limits of inductive methods the insights derived from the analysis of phenomena were taken to be subject to potentially open-ended further refinement, just as Newton envisaged (see Smith 2002, 160-161). So we can keep reducing our ignorance, but as Hume warns us, we should not hope to reveal ultimate knowledge of causes (EHU 4.12, see also e.g. $\mathrm{T}$ 1.2.5.25). They also agree that explanatory hypotheses unfounded on the analysis of experience are of no epistemic value. One consequence of the ban on explanatory hypotheses was the emphasis placed on explaining phenomena increasingly in their own terms as opposed to the speculative metaphysics of some underlying hypothetical reality (Gaukroger 2014, 20-28) - let it be the world of Aristotelian essences or that of allegedly clearly intuited Cartesian simple natures.

In Newton's epistemic ideal speculative metaphysics is suppressed by what is actually observed and this tendency extends to metaphysical concepts: Newton transforms them, e.g. questions concerning space and God, into empirical questions of experimental natural philosophy (see Stein 2000, 261-262, 269-270, 277). This is what Schliesser (2011) calls "Newton's challenge to philosophy": a challenge that is posed to the concept of causation too: despite Newton's famous denial in a letter of 1692 to Richard Bentley, he did believe in action at a distance (see Henry 2011), i.e. he relied on a concept of causation that did not require the spatial contiguity of cause and effect. This was a crucial metaphysical breach with the then dominant

11 Given the Hume's account of the practices and metaphysics of mathematical knowledge, even the certainty and demonstrativity of mathematics can also be effectively questioned (see Demeter 2019b).

12 The literature on Hume's relation to Newton is now voluminous. For the most recent overview see Schliesser and Demeter 2020. 
concept of mechanical causation (see e.g. Ott, 2009) that allowed only for contact causation within the sphere of intelligible processes. The requirement of contiguity is still explicitly required for causation in the Treatise (see e.g. $\mathrm{T}$ 1.3.14.1, 1.3.15.3, Coventry 2006, 84-85), but it is not at all mentioned as a necessary condition of causal relation in the Enquiry.

Hume's analysis can be read as an "empirical deduction"13 of a metaphysical concept in the spirit of Newton's challenge: a genealogy that reveals its traceable empirical content. Hume's billiard-ball example is mentioned only passingly in the Treatise, but it is thoroughly exploited and becomes crucial in the Enquiry (T 1.13.14.18, Abs.9, and EHU 4.8-10, $5.11,7.6,21,28,30)$. Its analysis, and the emphasis Hume puts on it, in the Enquiry supports the removal of the contiguity condition, because the crucial lesson that one can draw from the analysis of the experience of collision is that contact causation is not any more intelligible than action at a distance. In the Enquiry, constant conjunction and the ensuing idea of necessary connection are at the heart of Hume's analysis of 'cause' and it can accommodate Newtonian gravity as legitimate in causal explanations - even without specifying contact mechanisms by which it exerts its influence. This legitimacy cannot be provided by the Treatise's account.

Beyond these methodological and metaphysical convergences and divergences there is a gap between Hume's and Newton's ideologies of knowledge, i.e. between the frames within which they see the significance and meaning of inquiry and how it derives inspiration and legitimacy. The dominant stance of Newtonians in Scotland and abroad was in concert with the dictum in the General Scholium in the Principia: "to treat of God from phenomena is certainly a part of natural philosophy" (Newton 2004, 92). In this spirit many of them were working on fulfilling Newton's prophecy at the end of the Opticks, that following his method of analysis and synthesis "the Bounds of Moral Philosophy will also be enlarged." This enlargement should proceed through the perfection of natural philosophy, which consists in its increasing contribution to our knowledge of the attributes and intentions of God: "For so far as we can know by natural philosophy what is the first cause, what power he has over us, and what benefits we receive from him, so far our duty towards him, as well as that towards one another, will appear to us by the light of nature" (Newton 2004, 140).

Hume did not share the high hopes of Scottish "providential naturalism" for epistemic benefits concerning transcendence (for a summary see Broadie 2004, 41-43). The articulation of his stance in this respect is a leading theme of the Enquiry, and it might be labelled as methodological agnosticism that undermines the epistemic authority of moral (EHU Section 8/2) and natural inquiries (EHU 11) into the matters of transcendence, and of scriptural (or

13 This is an intended allusion to Kant's "transcendental deduction" of the categories. On some of the affinities and divergences of Hume's and Kant's project see Demeter 2016, ch. 3. 
Biblical) inquiries (EHU 10) into matters of nature. The common lesson that Hume can offer to them is that they cannot be sources of epistemic value. This agnosticism is typically not expressed in explicit methodological commitments, but it is exhibited throughout various contexts. Hume comes close to a clear formulation of this stance when he says that "[w]e can never be allowed to mount up from the universe, the effect, to Jupiter, the cause; and then descend downwards, to infer any new effect from that cause" (EHU 11.14). It is easy to read this as a ban, contrary to Newton's advice in Query 31 of the Opticks on extending the method of analysis and synthesis so as to reach conclusions concerning transcendent matters. As Hume considers this method the only appropriate method of reasoning about empirical matters, he thereby renders the properties of transcendent existence inaccessible by experimental reasoning (for more details see Demeter 2016: ch. 5 and 179-182).

For Hume, the "only immediate utility of all sciences, is to teach us, how to controul and regulate future events by their causes" (EHU 7.29). This is common to moral and natural philosophy, and this is how we can expect improvement in society from the cultivation of the "accurate", "abstruse", "profound" and "subtile" forms of philosophy (EHU 1.4-5, 9). But beyond this instrumental utility (and the intellectual pleasure we can derive from pursuing philosophical enterprises (see e.g. EHU 1.10, T 2.3.10.4)), we are in vain to extend the boundaries of science to transcendent matters. Even if God is the author of the Book of Nature, he did not equip us with the necessary tools for reading it. Hume thus rejects Newton's vision concerning the study of God through nature and the enlargement of moral philosophy through our improved knowledge of the first cause.

\section{Conclusion}

In this paper I could take only the first steps towards an explication of Hume's epistemic ideal by outlining its critical edge directed against theninfluential alternatives. The clarification of central epistemic concepts and the epistemic burden they can carry, as well as the prospects and limits of the epistemic genres organized by them, must be left to other occasions. Still, the picture drawn here, despite being only partial, can still reveal some central features of Hume's epistemic ideal. Close relatives of these features are easily discernible in the self-image of modern science that emerged gradually as a result of putting forward, and putting into use, alternative conceptions and practices of knowledge production.

These features include Hume's empiricism which is moderately optimistic about advancing knowledge claims with respect to unobserved structures and processes, and completely pessimistic in those respects where no empirical analogies can be exploited for analytical and inferential purposes. Although empirical inquiry can only aspire to a degree of certainty 
that falls short of being demonstrative, it can still be certain enough to be unanimously reliable and instrumentally useful. The Humean ideal does not favour mathematization: although mathematical representation and analysis of phenomena is not against Hume's taste, mathematics cannot be the guide or model of inquiry and discovery into matters of fact. Mathematics is a field of knowledge and relies on a form of reasoning that is categorically distinct from empirical reasoning (see Demeter 2019b, Slavov 2017), so it develops in complete isolation from the empirical sciences. Against the background of Hume's epistemic ideal, the thorough mathematization of natural philosophy in the following centuries could have testified only what Wigner (1960) famously termed "the unreasonable effectiveness of mathematics in the natural sciences".

Yet, the main lesson Hume offers is ideological and has been incorporated into the self-image of modern science: insofar as we study nature in accordance with sober methodological rules (to which Newton and his followers assents as well), we cannot hope for any knowledge of transcendent matters. If we are to stick to the, by Newton's standards, best method of reasoning that the "nature of things admits of" - namely induction based on experience, observation and analogy - then we have to give up the Newtonian ideology of natural philosophy: its religious frame of significance is to be replaced by an entirely secular one - that of Humean instrumentality.

\section{References}

CSM - The Philosophical Writings of Descartes, Vols. 1 and 2, translated by John Cottingham, Robert Stoothof, and Dugald Murdoch, Cambridge: Cambridge University Press, 1985.

EHU - An Enquiry concerning Human Understanding, ed. Tom L. Beauchamp, Oxford: Oxford University Press, 2000.

$\mathrm{T}$ - A Treatise of Human Nature, 2 vols., eds. David Fate Norton and Mary J. Norton, Oxford: Oxford University Press, 2007.

Barfoot, Michael, 1990. "Hume and the Culture of Science" in M.A. Stewart (ed.), Studies in the Philosophy of Scottish Enlightenment, Oxford: Oxford University Press.

Broadie, Alexander, 2004. "Reid in Context" in T. Cueno and R. van Woudenberg (eds.), The Cambridge Companion to Thomas Reid, Cambridge: Cambridge University Press, 31-52.

Buckle, Stephen, 2001. Hume's Enlightenment Tract, Oxford: Clarendon Press.

Cohen, I.B., 1980, The Newtonian Revolution, Cambridge: Cambridge University Press. 
Coventry, Angela, 2006. Hume's Theory of Causation: A Quasi-Realist Interpretation, London: Continuum.

Demeter, Tamás, 2016. David Hume and the Culture of Scottish Newtonianism: Methodology and Ideology in Enlightenment Inquiry, Leiden: Brill.

Demeter, Tamás, 2019a. "Hume's Science of Mind and Newtonianism" in Eric Schliesser and Christopher Smeenk (eds.), The Oxford Handbook of Newton, https://doi.org/10.1093/oxfordhb/9780199930418.013.19

Demeter, Tamás, 2019b. "Hume on the Social Construction of Mathematical Knowledge”, Synthese 196/9, 3615-3631.

Demeter, Tamás, 2020. “The Science in Hume’s Science of Man”, Journal of Scottish Philosophy, 18/3, 257-271.

Demeter, Tamás, 2021. "Fodor's Guide to the Humean Mind", Synthese, https://doi.org/10.1007/s11229-021-03028-4

Demeter, Tamás, Benedek Láng and Dániel Schmal, 2016. "Scientia" in Marco Sgarbi (ed.), Encyclopedia of Renaissance Philosophy, Cham: Springer, https://link.springer.com/referenceworkentry/10.1007\%2F978-3-319-028484_266-1

Garber, Daniel, 1992. Descartes' Metaphysical Physics, Chicago: University of Chicago Press.

Garber, Daniel, 2001. Descartes Embodied, Cambridge: Cambridge University Press.

Gaukroger, Stephen, 2014. "Empiricism as a Development of Experimental Natural Philosophy" in Zvi Biener and Eric Schliesser (eds.), Newton and Empiricism, New York: Oxford University Press.

Guicciardini, Nicoló, 2009. Isaac Newton on Mathematical Certainty and Method, Cambridge, Mass.: MIT Press.

Harris, James A., 2015. Hume: An Intellectual Biography, Cambridge: Cambridge University Press.

Henry, John, 2011. "Gravity and De Gravitatione: The Development of Newton's Ideas on Action at a Distance", Studies in History and Philosophy of Science 42/1, 11-27.

Jardine, Lisa, 1974. Francis Bacon and the Art of Discourse, Cambridge: Cambridge University Press.

Landy, David 2018. Hume's Science of Human Nature: Scientific Realism, Reason, and Substantial Explanation. London: Routledge.

Newton, Isaac, 1672. "A Letter of Mr. Isaac Newton...Containing His New Theory of Light and Colours," Philosophical Transactions of the Royal Society 6, No. 80, 3075-87. 
Newton, Isaac, 2004. Philosophical Writings, Cambridge: Cambridge University Press.

Norton, David Fate and Norton, Martha, 2007. "Historical Account of a Treatise of Human Nature from its Beginnings to the Time of Hume's Death.” In Hume, T, vol. 2, Oxford: Clarendon Press, 433-588.

Ott, Walter, 2009. Causation and Laws of Nature in Early Modern Philosophy, Oxford: Oxford University Press.

Pasnau, Robert, 2013. "Epistemology Idealized", Mind 122/488, 987-1022.

Pasnau, Robert, 2017. After Certainty: A History of Our Epistemic Ideals and Illusions, Oxford: Oxford University Press.

Perinetti, Dario, 2018. "Hume at La Flèche: Skepticism and the French Connection", Journal of the History of Philosophy 56/1, 45-74.

Qu, Hsueh M., 2020. Hume's Epistemological Evolution, Oxford: Oxford University Press.

Reid, Thomas, 1872. The Works of Thomas Reid, 2 vols. $7^{\text {th }}$ ed. Edinburgh: Maclachlan and Stewart.

Salmieri, Gregory, 2014. "Aristotelian Episteme and the Relation between Knowledge and Understanding", Metascience 23/1, 1-9.

Schliesser, Eric, 2011, "Newton's Challenge to Philosophy: A Programmatic Essay," HOPOS: The Journal of the International Society for the History of Philosophy of Science 1/1, 101-28.

Schliesser, Eric and Demeter, Tamás, 2020. "Hume's Newtonianism and AntiNewtonianism", Stanford Encyclopedia of Philosophy, https://plato.stanford. edu/entries/hume-newton/

Sgarbi, Marco, 2013. The Aristotelian Tradition and the Rise of British Empiricism: Logic and Epistemology in the British Isles (1570-1689), Cham: Springer.

Shapiro, Alan E., 1993. Fits, Passions, and Paroxysms: Physics, Method, and Chemistry and Newton's Theories of Colored Bodies and Fits of Easy Reflection, Cambridge: Cambridge University Press.

Shepherd, Christine M., 1982. "Newtonianism in Scottish Universities in the Seventeenth Century", in R.H. Campbell and A. Skinner (eds.), The Origins and Nature of the Scottish Enlightenment, Edinburgh: John Donald.

Slavov, Matias, 2016. "Newtonian and Non-Newtonian Elements is Hume", Journal of Scottish Philosophy 14/3, 275-296.

Slavov, Matias, 2017. "Hume's Fork and Mixed Mathematics", Archiv für Geschichte der Philosophie 99/1, 102-119. 
Smith, George E., 2002. "The Methodology of the Principia" in I.B. Cohen and George E. Smith (eds.), The Cambridge Companion to Newton, Cambridge: Cambridge University Press, 138-73.

Smith, Kurt, 2010. Matter Matters: Metaphysics and Methodology in the Early Modern Period, Oxford: Oxford University Press.

Smith, Robin, 2017. "Aristotle's Logic", Stanford Encyclopedia of Philosophy, https://plato.stanford.edu/entries/aristotle-logic/

Stewart M.A., 2005, "Hume's Intellectual Development" in Marina FrascaSpada and P.J.E. Kail (eds.), Impressions of Hume, Oxford: Oxford University Press.

Turnbull, H. W., ed. 1959. The correspondence of Isaac Newton I. 1661-1675. Cambridge: Cambridge University Press.

Turnbull, H. W., ed. 1960. The correspondence of Isaac Newton II. 1676-1687. Cambridge: Cambridge University Press.

Wigner, Eugene, 1960, "The Unreasonable Effectiveness of Mathematics in the Natural Sciences", Commun. Pure Appl. Math. 13/1, 1-14.

Wilson, David B., 2009. Seeking Nature's Logic: Natural Philosophy in the Scottish Enlightenment, University Park: Penn State University Press.

Wright, John P., 2009. Hume's A Treatise of Human Nature: An Introduction, Cambridge: Cambridge University Press.

Zemplén, Gábor Á. and Demeter, Tamás, 2010. "Being Charitable to Scientific Controversies: On the Demonstrativity of Newton's Experimentum Crucis", Monist 93/4, 640-656. 